\title{
RECESSIVE SEX-LINKED INHERITANCE OF EXTERNAL OPHTHALMOPLEGIA AND MYOPIA COINCIDENT WITH OTHER DYSPLASIAS*
}

$\mathrm{BY}$

\author{
Alejandro Salleras and Julio César Ortiz de Zárate \\ From the Department of Ophthalmology and the Institute of \\ Neurosurgery, University of Buenos Aires, Argentina.
}

DifFEREN authors have reported several cases of congenital external ophthalmoplegia, some of which were myopic. No one, however, has paid special attention to this occurrence. Familial external ophthalmoplegia has been reported as inherited in two forms: dominant and recessive.

The fact that all our cases with ophthalmoplegia were myopic, the special form of transmission of the pathological gene, and the presence of a number of stigmata in the affected subjects and in the carriers of the pathological gene, are the most interesting features of our communication.

The ophthalmological picture of our four patients is strikingly similar in all (Fig. 1). They present the following characteristics:

(1) Complete bilateral ptosis.

(2) Almost complete, or complete, bilateral external ophthalmoplegia.' Slight lateral movements are obtainable in some of them, but they are scarce and do not reach $20^{\circ}$.

(3) Divergent squint is present in three cases (III, 4; III, 6; IV, 5), and convergent squint in the other (IV, 6).

(4) The pupils are eccentric, dyscoric, and anisocoric. The light reflex is normal in seven eyes and absent in the eighth. The accommodative reflex is very difficult to obtain because of the lack of convergence and the existence of high myopia.

(5) Myopia of high degree in the three older patients and of slight degree in the youngest; fairly good visual acuity without glasses (because of the stenopeic slit produced by the ptosis) only very slightly improved by their use.

(6) Myopic fundus alterations (sta phylomata and Foerster-Fuchs macular spot).

()f the living male subjects, only one (IV, 3) has normal eyes (Fig. 1a): two other afflicted males died, one in early

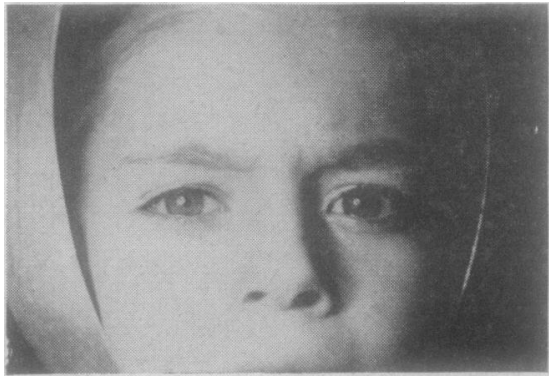

FIG. i $(a)$ - - IV, 3. Normal male. childhood (IV, 7), the other at the age of 46 years. (Generation II). The genealogical tree (Fig. 2, p. 664) shows that most of the men are phenotypically affected, and that all the women are phenotypically

${ }^{*}$ Received for publication July 7, 1950. 

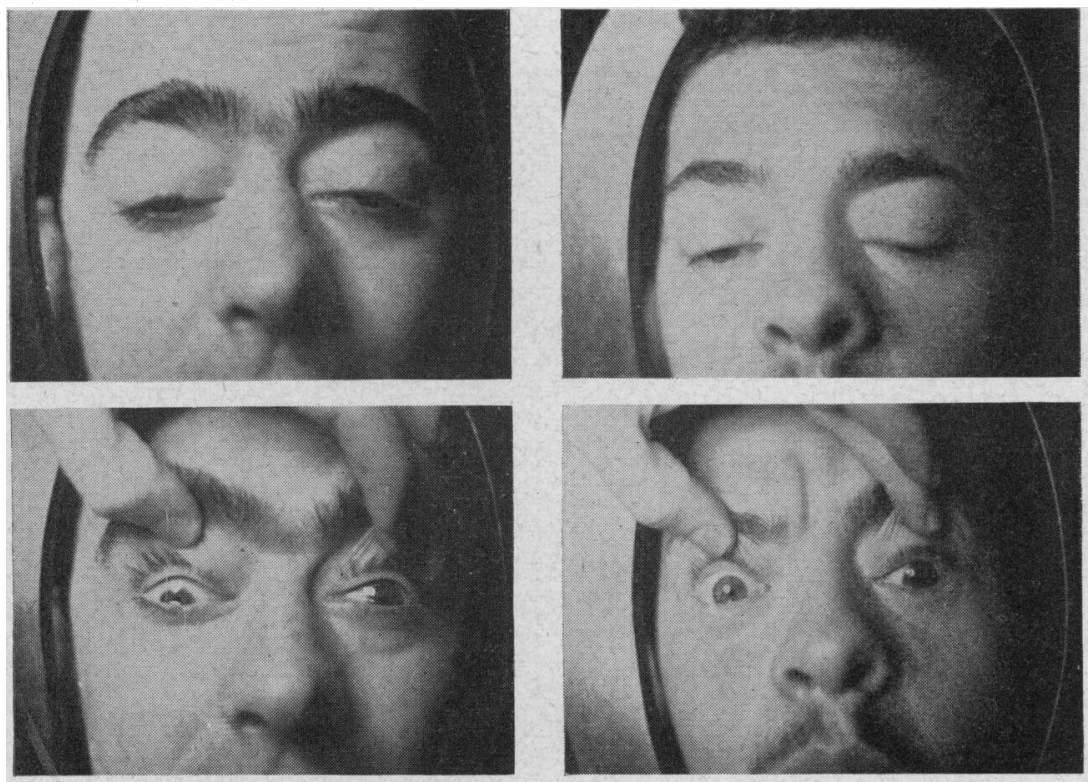

III, 4.

III, 6 .
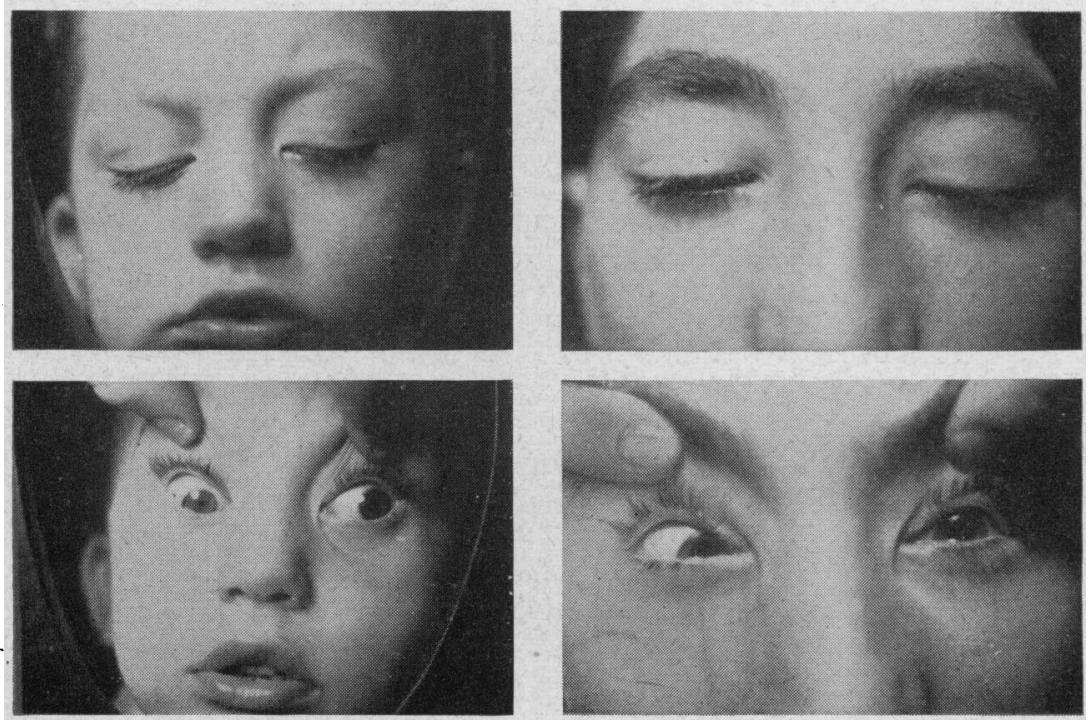

IV, 5 .

IV, 6.

Fig. 1.-Four afflicted male members of the family. 


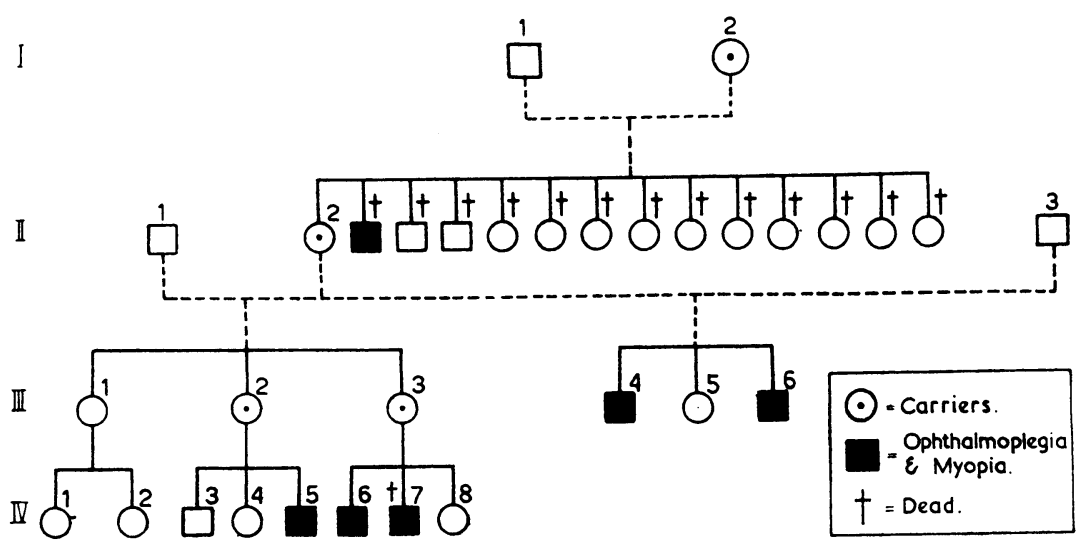

FIG. 2.-Recessive sex-linked pedigree of external ophthalmoplegia and myopia.

healthy. Some of the women are genotypically affected and therefore transmit the gene. The inheritance of this gene in this family is recessive and sex-linked. As far as we have been able to discover in the literature there is no earlier reference to inheritance of this type for this particular disease.

The clinical and neurological examination carried out by one of us (J.C. O. de Z.) on all fourteen living members of the family, enabled us to detect a number of signs enumerated in Fig. 3 (opposite). As may be observed, the stigmata are apparent only in the affected males and in the female transmitters of the pathological gene. The most interesting symptom is the absence of knee and ankle jerks. From the presence or absence of these reflexes in the women of this family, we have been able to point out which persons are transmitters of the pathological gene and which are not.

This point is of great practical interest because, basing our replies on the Mendelian laws and the degree of purity in the pedigree, we can say which members of the family may, and which may not, have issue without danger of bringing more afflicted children into the world. Thus the family may survive through its fittest members, for we shall be able to assure the homozygotes that their descendants will be born completely healthy. We can advise the heterozygotic women that half of their descendants will be born afflicted or as transmitters of this disease. Afflicted males can be told that all their male descendants will be healthy non-transmitters, and that a study of the patellar reflexes will determine which of their daughters are transmitters of the ophthalmoplegic gene. 


\begin{tabular}{|c|c|c|c|c|c|c|c|c|c|c|c|c|}
\hline NAME & & 1 & 2 & 3 & 4 & & $\begin{array}{ll}5 & \\
b & c\end{array}$ & 6 & 7 & 8 & 9 & 10 \\
\hline E. L.d.D.y F. & $\odot$ & - & \pm & + & - & -1 & -- & $?$ & + & - & + & - \\
\hline E.d.P. & $\odot$ & - & - & \pm & - & - & - \pm & $?$ & - & - & + & + \\
\hline E. N. & $\odot$ & - & - & + & + & -1 & -+ & - & - & - & + & - \\
\hline A.M. & $\odot$ & - & - & + & - & $\square$ & 7 & $?$ & - & + & + & - \\
\hline N. 0 . & 0 & - & - & + & - & + & -1 & $?$ & + & - & + & 二 \\
\hline N.deP. & 0 & - & - & - & - & - & $-1+$ & - & - & - & - & - \\
\hline J.M.de.P. & 0 & - & - & - & - & - & $-1-$ & - & - & \pm & - & - \\
\hline N.E.N. & 0 & - & - & - & - & -1. & -- & - & - & - & - & - \\
\hline M.C.M. & 0 & - & - & - & - & - & - & - & - & - & - & - \\
\hline P. V. & $\boldsymbol{D}+$ & + & & & & H & & & & & & \\
\hline A. 0. & $\mathbf{0}$ & + & + & + & + & -1 & -1 & + & + & - & - & + \\
\hline A. D. & a & + & + & + & + & + & ++ & + & + & + & - & + \\
\hline N.O.N. & $\square$ & - & - & - & + & - & $-1-$ & $\rightarrow$ & - & - & - & - \\
\hline O. N. & 口 & + & + & + & + & + & ++ & + & - & - & - & + \\
\hline B. M. & 口 & + & + & + & - & & ++ & $?$ & - & + & - & + \\
\hline M. & $\mathbf{v}$ & + & & & & & & & & & & \\
\hline
\end{tabular}

FIg. 3.- Ocular and extra-ocular signs in sixteen members of the family.

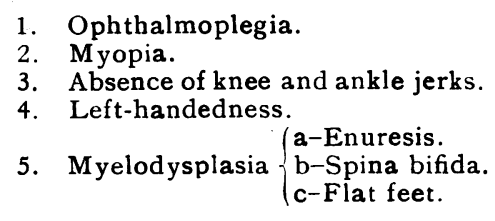

6. Cardiac malformation.

7. Hernia and varices.

8. Anomalous occlusion of the teeth.

9. Goitre.

10. Thoracic malformation.

All the members of this family are natives of Argentina, and it is impossible to investigate retrospectively the exact moment that the mutation or translocation of the gene from an autosome to the unpaired part of the $\mathrm{X}$ chromosome occurred. It is to be remembered that this gene is recessive, and that in an autosome if the unions were not consanguineous it could have remained for many generations without manifesting itself. Because of the frequent illegal unions in this pedigree, it was impossible to trace any ancestors further than the first generation of the given tree. Every one of the signs evident in these patients could be accepted as dysrhaphic, but the absence of one (ophthalmoplegia) in the women, and its presence in the men, would prevent us from accepting all these stigmata as the result of one pleotropic gene.

The known position of the gene of hereditary sex-linked myopia in the non-homologous part of the $\mathrm{X}$ chromosome, the circumstance that all the affected members of this family are myopic, and the fact that a study of the literature reveals a marked 
666 Alejandro Salleras and Julio César Ortiz de Ż́rate

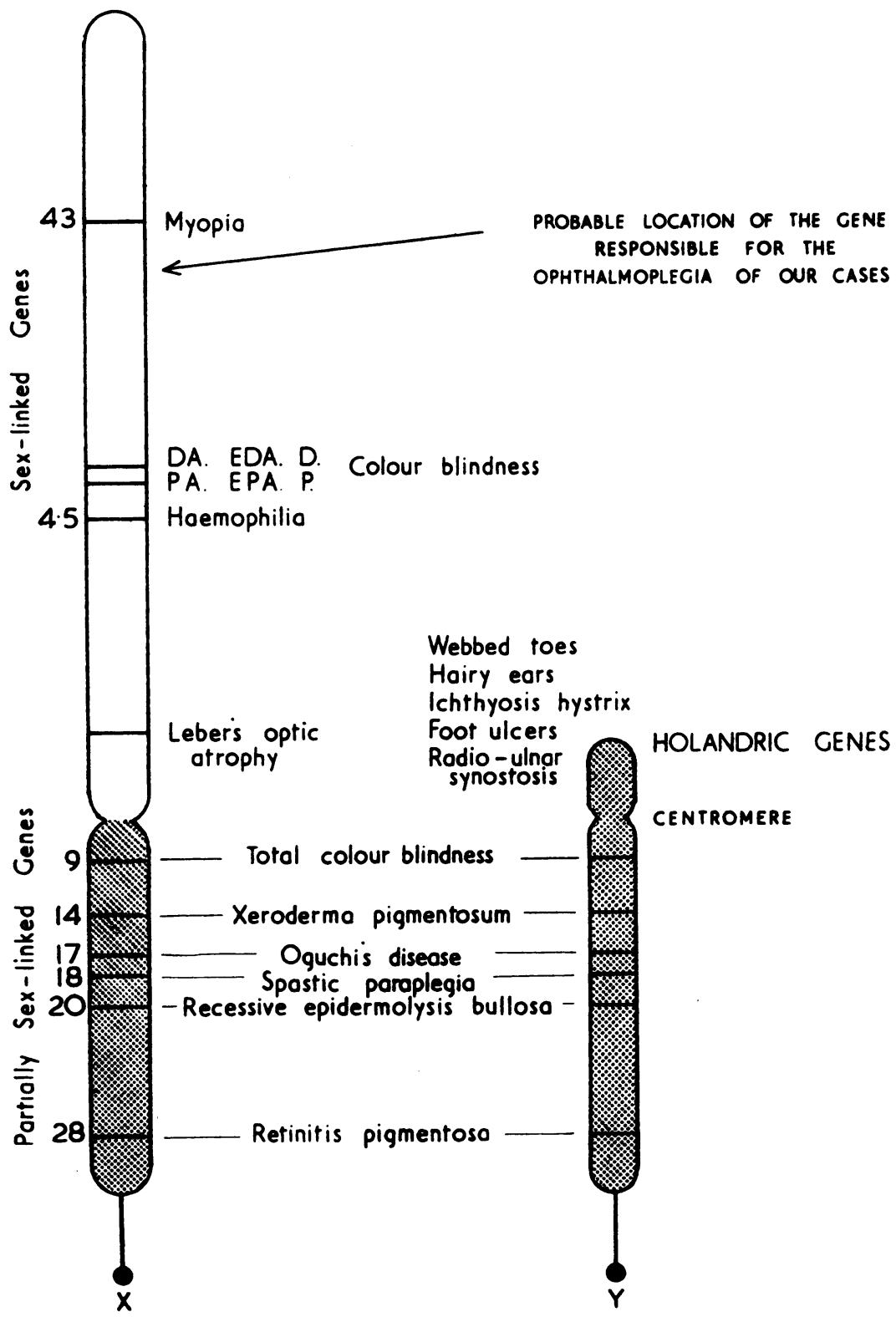

FIG. 4.-Diagram of the sex-chromosomes and some of their contained genes. (Courtesy of Macmillan, New York, and Gates, 1946.) 
tendency for the co-existence of these two signs (ophthalmoplegia and myopia), suggest that the probable location of the pathological gene of our cases is close to that of the myopia. This location is shown in Fig. 4, adapted from Gates (1946).

\section{Summary}

A report is presented of a family with heriditary, sex-linked, congenital ophthalmoplegia. Six males out of seven had the disease. All the females were ophthalmologically normal. The coincidence of other signs (myopia, absence of tendon reflexes, etc.) suggests interesting conclusions.

This family is believed to be the first reported with this type of inheritance.

\section{REFERENCE}

Gates. R. R. (1946). ' "Human Genetics", Macmillan, New York, Vol. I, p. 81. 